\title{
ELABORAÇÃO E CARACTERIZAÇÃO FÍSICO-QUÍMICA E SENSORIAL DE IOGURTE PREBIÓTICO DE TAMARINDO
}

\author{
Elaboration and physical-chemical and sensory \\ characterization of tamarind prebiotic yogurt
}

\author{
Marcelino Maia Bessa $^{1 *}$, Alvaro Gustavo Ferreira da Silva ${ }^{l}$
}

\begin{abstract}
RESUMO
Os consumidores vêm se tornando cada vez mais exigentes na busca por alimentos que, além de nutritivos, promovam saúde e bem-estar. Assim, a indústria de laticínios tem buscado desenvolver produtos com essas características, os alimentos funcionais. Diante disso, objetivou-se com o presente trabalho a elaboração e caracterização, físico-química e sensorial, de iogurtes de tamarindo enriquecidos com prebióticos (inulina e fruto-oligossacarídeo). Foram elaboradas três formulações: A (sem adição dos prebióticos), B (acrescido de 3\% de inulina) e C (com 3\% de frutooligossacarídeo) que, por sua vez, foram submetidas às análises físico-químicas de umidade, cinzas, pH, acidez titulável e lipídeos; e à análise sensorial de aceitação e intenção de compra. A partir dos resultados, pode-se perceber que não houve diferença estatística nos parâmetros avaliados, exceto a umidade, que apresentou uma diferença entre as amostras. Quanto aos resultados da avaliação sensorial, observou-se que, estatisticamente, a adição dos prebióticos não promoveu interferência significativa $(\mathrm{p}<0,05)$ em nenhum dos quesitos sensoriais avaliados, mostrando que todas as amostras foram bem aceitas, com índice de aceitabilidade $>70 \%$. As formulações com adição dos prebióticos obtiveram aceitações semelhantes ao produto padrão, além de apresentar boas expectativas de comercialização. Dessa forma, foi possível perceber a viabilidade da adição de prebióticos em formulações de iogurte saborizado com tamarindo, contribuindo para a diversificação do setor lácteo e de alimentos funcionais.
\end{abstract}

Palavras-chave: inulina; fruto-oligossacarídeo; Tamarindus indica.

1 Instituto Federal de Educação, Ciência e Tecnologia do Rio Grande do Norte, Campus Pau dos Ferros, BR 405, s/n, 59900-000, Pau dos Ferros, RN, Brasil. E-mail: marcelino.maia.18@ outlook.com

* Autor para correspondência. 


\begin{abstract}
Consumers are becoming increasingly demanding in the search for foods that, in addition to being nutritious, promote health and well-being. Thus, the dairy industry has sought to develop products with these characteristics, functional foods. Therefore, the objective of this work was the elaboration and physical-chemical and sensorial characterization of tamarind yoghurts enriched with prebiotics (inulin and fructooligosaccharide). Three formulations were prepared: A (without addition of prebiotics), B (plus 3\% inulin) and $\mathrm{C}$ (with 3\% fructooligosaccharide), which in turn were submitted to physical-chemical analyzes of moisture, ashes, $\mathrm{pH}$, titratable acidity and lipids; and the sensory analysis of acceptance and purchase intention. From the results, it can be noticed that there was no statistical difference in the evaluated parameters, except for the moisture content, which showed a difference between the samples. Regarding the results of the sensory evaluation, it was observed that, statistically, the addition of prebiotics did not promote significant interference $(p<0.05)$ in any of the sensorial aspects evaluated, showing that all the samples were well accepted, with $>70 \%$. The formulations with addition of the prebiotics obtained similar acceptances to the standard product, besides presenting good expectations of commercialization. In this way, it was possible to perceive the viability of the addition of prebiotics in tamarind-flavored yogurt formulations, contributing to the diversification of the dairy sector and functional foods.
\end{abstract}

Keywords: inulin; fructooligosaccharides; Tamarindus indica.

\section{INTRODUÇÃO}

A demanda constante dos consumidores por uma alimentação mais saudável tem tornado o desenvolvimento de alimentos nutritivos e saudáveis uma das maiores prioridades da indústria alimentícia. Essa tendência contribui significativamente para a implantação de um novo conceito na área das ciências dos alimentos, denominado alimentação funcional (FONTES, 2013).

Nessa perspectiva, destacam-se os leites fermentados, que têm um elevado potencial para o desenvolvimento de novos produtos, principalmente por estarem associados à saúde. Este fator está relacionado com três características: as propriedades tecnológicas da matriz láctea, a elevada praticidade dos derivados lácteos e a relação que os consumidores fazem dos produtos lácteos com alimentação saudável (COSTA et al., 2013).
Dentre os leites fermentados, o iogurte é o mais conhecido e consumido no Brasil, obtido pela fermentação realizada pelos Streptococcus salivarius subsp. thermophilus e Lactobacillus delbrueckii subsp. bulgaricus, os quais podem acompanhar outras bactérias ácido-láticas. O mesmo apresenta aspectos nutricionais e sensoriais bastante atrativos para o consumidor, como por exemplo, a sua fácil digestão, a rica quantidade de cálcio e proteínas, além de minerais, como zinco e magnésio (ROJAS et al., 1993; GARCIA-MARTINEZ et al., 1998; MARTINEZ et al., 1998; KARAGULYUCEER et al., 1999).

$A$ adição de frutas também tem se mostrado uma favorável diversificação, pois proporciona aroma e sabor característicos da fruta, uma vez que nem todos os consumidores preferem o iogurte na sua forma natural (CARVALHO et al., 2010; BRAGA 
et al., 2012). As frutas consistem ainda como fonte principal de vitaminas, minerais e carboidratos solúveis, que podem ser adicionadas ao iogurte na forma de xarope ou em pedaços (MATSUURA; ROLIM, 2002; TACO, 2006).

O tamarindo (Tamarindus indica L) é originário da África, mas foi cultivado em diversas áreas tropicais. No Brasil, é encontrado principalmente no Nordeste, por apresentar um clima apropriado, onde destaca-se por suas propriedades nutricionais e medicinais, sendo comumente utilizado pela população no preparo de receitas caseiras (MESQUITA et al., 2012).

Outra maneira de agregar valor nutricional a produtos alimentícios baseia-se na inserção de ingredientes funcionais em sua formulação (OLIVEIRA et al., 2002). Com isso, surge a viabilidade da adição de prebióticos, sendo que os mais utilizados são a inulina e os fruto-oligossacarídeos (ESTEFE et al., 2008).

Os prebióticos são componentes alimentares seletivamente fermentados por populações de bactérias desejáveis, tais como Bifidobacterium sp., causando mudanças específicas na composição e/ou na atividade da microbiota intestinal, afetando beneficamente o hospedeiro e contribuindo em sua saúde e bem-estar (SAAD, 2006; SLAVIN, 2013).

Entre os carboidratos prebióticos disponíveis no mercado, a inulina tem ganhado destaque na comunidade científica em virtude de suas características e viabilidade de aplicação tecnológica, principalmente como substituinte de gordura, visando melhorar a consistência e cremosidade em produtos lácteos, leites fermentados, sobremesas e sorvetes (FONTES, 2013).

Outro prebiótico muito utilizado na indústria alimentícia são os fruto-oligossacarídeos (FOS), que são compostos de ocorrência natural em produtos de origem vegetal, mais conhecidos como açúcares não convencionais. Têm apresentado crescente utilização na indústria principalmente com o intuito de substituir parcialmente a sacarose (SILVA, 2008).

Dessa forma, objetivou-se com o presente trabalho a elaboração e caracterização, físicoquímica e sensorial, de três formulações de iogurte de tamarindo enriquecidos com os prebióticos inulina e fruto-oligossacarídeos, como forma de responder à demanda do consumidor por alimentação saudável e funcional.

\section{MATERIAL E MÉTODOS}

\section{Obtenção da matéria prima}

Para elaboração do iogurte, utilizou-se polpas de tamarindo (Nossa Fruta ${ }^{\circledR}$ ), leite UAT integral (Camponesa $\left.{ }^{\circledR}\right)$, açúcar $\left(\right.$ Cristal $\left.^{\circledR}\right)$ adquiridos no comércio da cidade de Encanto, $\mathrm{RN}$; cultura láctica (Rica Nata Ricaferm ${ }^{\circledR}$ YRO2), inulina (Orafti ${ }^{\circledR}$ ) e FOS (Fosvita ${ }^{\circledR}$ ) - adquiridos no comércio de Fortaleza, CE. Todos os componentes necessários foram então levados ao laboratório de Processamento de Leite e Derivados do IFRN - Campus Pau dos Ferros, onde deu-se início a elaboração e caracterização do produto.

\section{Preparo do concentrado de tamarindo}

O concentrado foi elaborado adicionando-se $50 \%$ de açúcar à polpa e aquecendo-a a $100{ }^{\circ} \mathrm{C}$ por 5 minutos, visando diminuir a percepção sensorial da acidez do tamarindo e conferir melhor consistência e viscosidade à polpa.

\section{Elaboração do iogurte}

A elaboração do iogurte foi realizada conforme metodologia descrita por Queiroz (2014), apresentada na Figura 1 e adaptada 
para incremento do concentrado do tamarindo e da quantidade de ingredientes não lácteos adicionados permitida pela legislação, que estabelece um limite máximo de 30\% (BRASIL, 2007).

Foram elaboradas três formulações que se diferenciavam pela presença ou não do prebiótico. Assim, elaborou-se a formulação A (controle) - sem adição de prebiótico, formulação B (contendo $3 \%$ de inulina) e formulação $\mathrm{C}$ (contendo $3 \%$ de FOS), com três repetições cada.

Para esse trabalho, utilizou-se 6 litros de leite, submetidos ao aquecimento a $90{ }^{\circ} \mathrm{C}$ por 5 minutos, com $7 \%$ de açúcar, tendo em vista uma breve termização do açúcar. Após o aquecimento, o leite foi resfriado a uma temperatura de $45^{\circ} \mathrm{C}$ para adição do fermento lácteo na concentração de $0,01 \%$ e misturado. Em seguida, o leite foi transferido para três potes de polietileno devidamente higienizados, cada um destinado a uma das formulações produzidas. Os potes foram então colocados em estufa incubadora Biochemical Oxygen Demand (BOD) à temperatura de $45^{\circ} \mathrm{C}$, proporcionando uma condição ótima para o crescimento dos microrganismos fermentadores, permanecendo nessa condição até atingir pH entre 3,6 e 4,5.
Após a fermentação, fez-se o resfriamento a $10{ }^{\circ} \mathrm{C}$, quebrou-se o coágulo formado e adicionou-se o concentrado de tamarindo na proporção de $20 \%$ (concentração determinada com base em testes preliminares). Logo após, adicionou-se a inulina na concentração de 3\% (formulação B) e FOS a 3\% (formulação $\mathrm{C}$ ), permanecendo a formulação controle sem a adição dos prebióticos. As formulações foram então acondicionas a $7^{\circ} \mathrm{C}$, para posterior realização das análises físicoquímicas e sensorial.

\section{Caracterização físico-química do concen- trado de tamarindo e das formulações de iogurte}

O concentrado e as formulações de iogurte foram submetidos às análises físico-químicas, em triplicata, nos Laboratórios de Análises Físico-químicas do IFRN - Campus Pau dos Ferros. No concentrado, avaliou-se os parâmetros teor de umidade, $\mathrm{pH}$, acidez total titulável, cinzas e sólidos solúveis totais. Nas formulações de iogurte, foram analisados os parâmetros citados acima, exceto sólidos solúveis totais e acrescentando-se a quantificação do teor lipídeos. Para a determinação dos lipídeos, utilizou-se a metodologia descrita

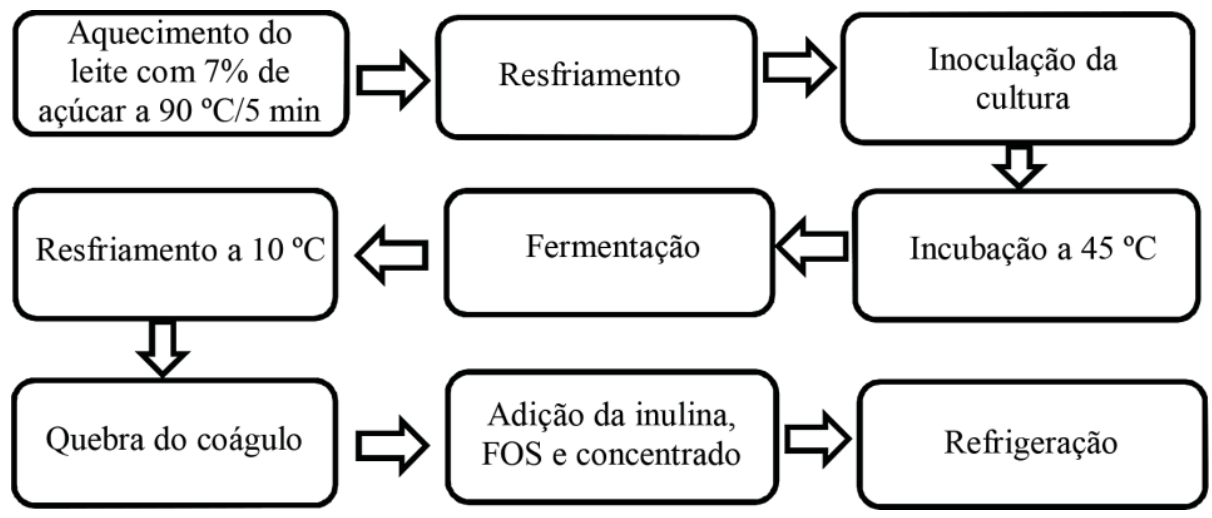

Fonte: Adaptado de Queiroz (2014).

Figura 1 - Fluxograma de elaboração do iogurte de tamarindo 
por Folch et al. (1957), e para as demais seguiu-se as recomendações do Instituto Adolfo Lutz (2008).

\section{Análise sensorial}

As amostras foram analisadas por 60 provadores voluntários não treinados, de ambos os sexos, consumidores de iogurte, compostos por alunos e funcionários da instituição e com faixa etária de 17 a 37 anos.

O teste de aceitabilidade do produto foi conduzido em bancadas individuais. Para cada provador realizou-se o seguinte procedimento: as amostras foram servidas em copos plásticos descartáveis de $50 \mathrm{~mL}$, codificados com números aleatórios de três dígitos sob a luz ambiente. Os julgadores foram orientados a beberem água à temperatura ambiente entre as amostras, para a limpeza do palato. Para avaliar os atributos sensoriais das amostras, utilizou-se uma ficha-resposta com os parâmetros sabor, cor, aroma, consistência e impressão global, organizados em uma escala hedônica de 1 (desgostei muitíssimo) a 9 (gostei muitíssimo); e intenção de compra, com notas variando de 1 (com certeza não compraria) a 5 (com certeza compraria). Com base nos resultados, calculou-se o índice de aceitabilidade dos produtos de acordo com a metodologia de Dutcosky (2007), a partir da fórmula $I A(\%)=A .100 / B$, onde $\mathrm{A}=$ média dos atributos e $\mathrm{B}$ a maior nota obtida.

\section{Análise estatística}

Os dados das análises físico-químicas e sensorial foram analisados com auxílio do software Assistat 7.7. através da análise de variância (ANOVA), comparando-se as médias pelo teste de Tukey com nível de $5 \%$ de significância $(\mathrm{p}<0,05)$.

\section{RESULTADOS E DISCUSSÃO}

\section{Resultados físico-químicos do concentrado de tamarindo}

Os resultados das análises físicoquímicas do concentrado de tamarindo podem ser observados na Tabela 1.

Tabela 1 - Parâmetros físico-químicos do concentrado de tamarindo

\begin{tabular}{lc}
\hline \multicolumn{1}{c}{ Análises } & $\begin{array}{c}\text { Média } \pm \\
\text { desvio padrão* }\end{array}$ \\
\hline $\mathrm{pH}$ & $2,91 \pm 0,01$ \\
$\begin{array}{l}\text { Acidez titulável }(\%) \\
\text { (ácido tartárico) }\end{array}$ & $2,33 \pm 0,00$ \\
$\begin{array}{l}\text { Sólidos Solúveis } \\
\text { Totais }\left({ }^{\circ} \text { Brix }\right)\end{array}$ & $44,5 \pm 0,00$ \\
Umidade $(\%)$ & $29,82 \pm 0,27$ \\
Cinzas $(\%)$ & $0,43 \pm 0,08$ \\
\hline
\end{tabular}

Com relação ao $\mathrm{pH}$, pode-se perceber que foi encontrado um valor muito baixo, como já era esperado. Esse baixo valor pode influenciar principalmente na sua conservação, além de influenciar no $\mathrm{pH}$ do produto final, quando utilizado como matéria prima.

O teor de acidez obtido foi de 2,33, semelhante ao obtido por Alves et al. (2013), ao avaliarem o teor de acidez do concentrado de tamarindo destinado a produção de um fermentado alcoólico e obterem um teor de $2,43 \%$.

Quanto à umidade e aos sólidos solúveis totais (SST), obteve-se valores de $29,82 \%$ e $44,5^{\circ}$ Brix, respectivamente. Esses valores diferem de Canuto et al. (2010), que encontraram teores de $75 \%$ para umidade e 24 ( ${ }^{\circ}$ Brix) para SST ao analisarem a polpa do tamarindo. Essa diferença é proveniente justamente do acréscimo de açúcar à polpa para produção do concentrado no presente 
trabalho. E, como esperado, quanto mais se adiciona sólidos à polpa, mais a umidade é reduzida.

Para o teor de cinzas, apesar da Tabela Brasileira de Composição de Alimentos (TACO, 2006) afirmar que o tamarindo tem capacidade de apresentar cinzas acima de $1 \%$, pode-se perceber que o valor encontrado para este parâmetro foi inferior, apresentando percentual 0,43\%. É importante ressaltar que a composição das cinzas pode variar de acordo com a espécie de cada fruta e nem sempre corresponde a quantidade de minerais totais, já que esses podem ser perdidos por volatilização (CECCHI, 2003).

\section{Resultados físico-químicos do iogurte}

Após a elaboração dos iogurtes, os mesmos foram submetidos à caracterização físicoquímica, conforme apresentado na Tabela 2.

Os resultados médios de $\mathrm{pH}$ não apresentaram diferenças significativas entre as três formulações e se enquadram na faixa recomendada segundo a Instrução Normativa n 46 de 24 de outubro de 2007 do MAPA, que estabelece o $\mathrm{pH}$ ideal para identidade e qualidade do iogurte entre 3,6 e 4,5 (BRASIL, 2007). Os valores obtidos neste estudo podem ser justificados principalmente pela adição do concentrado de tamarindo, uma vez que o mesmo apresenta valor de $\mathrm{pH}$ de 2,91.

Quanto ao parâmetro de acidez, não ocorreu diferença significativa entre as amostras, além de encontrarem-se de acordo com a legislação, que estabelece a acidez ideal em ácido láctico para leites fermentados de 0,9 a $2,0 \%$ (BRASIL, 2007). Os resultados obtidos neste estudo foram semelhantes aos encontrados por Laguna; Egito (2006), que obteveram $1,10 \%$ de acidez ao estudar iogurte batido de leite de cabra adicionado de polpa de frutas tropicais, sendo o tamarindo um desses.

Com relação aos teores de umidade e cinzas, não existe padrão na legislação vingente. Porém, é possível observar que os resultados para umidade diferiram estatisticamente, apresentando uma redução desse teor nas formulações $\mathrm{B}$ e $\mathrm{C}$ em relação à padrão. Isso pode ter ocorrido devido a adição dos prebióticos, em virtude da capacidade higroscópica que possuem, promovendo uma maior retenção da água, além de ser um incremento de sólidos, resultando em uma menor umidade ao produto final. Santos et al. (2014) afirmam que iogurtes com adição de sólidos tendem a ter um valor de umidade inferior, concordando com os resultados mostrados para as formulações B e C, porém

Tabela 2 - Valores médios da caracterização físico-química das três formulações do iogurte

\begin{tabular}{ccccc}
\hline & \multicolumn{3}{c}{ Formulações } & Legislação \\
Análises & $\mathrm{A}$ & $\mathrm{B}$ & $\mathrm{C}$ & Brasil (2007) \\
\cline { 2 - 4 } $\mathrm{pH}$ & $3,85^{\mathrm{a}} \pm 0,04$ & $3,83^{\mathrm{a}} \pm 0,02$ & $3,79^{\mathrm{a}} \pm 0,01$ & $3,6-4,5$ \\
Acidez $(\%)$ & $1,11^{\mathrm{a}} \pm 0,00$ & $1,11^{\mathrm{a}} \pm 0,00$ & $1,10^{\mathrm{a}} \pm 0,00$ & $0,9-2,0$ \\
Umidade $(\%)$ & $83,72^{\mathrm{a}} \pm 0,04$ & $82,26^{\mathrm{b}} \pm 0,22$ & $82,60^{\mathrm{b}} \pm 0,03$ & - \\
Cinzas $(\%)$ & $0,66^{\mathrm{a}} \pm 0,03$ & $0,70^{\mathrm{a}} \pm 0,01$ & $0,68^{\mathrm{a}} \pm 0,01$ & - \\
Lipídeos $(\%)$ & $3,04^{\mathrm{a}} \pm 0,09$ & $3,14 \mathrm{v} \pm 0,09$ & $3,08^{\mathrm{a}} \pm 0,16$ & $3,0-5,9$ \\
\hline
\end{tabular}

*Formulação A (controle) - sem adição de prebiótico; Formulação B (3\% de inulina) e Formulação C (3\% de FOS). Valores expressos como média \pm desvio padrão. Letras iguais em uma mesma linha indicam que não há diferença significativa $(\mathrm{p}>0,05)$. 
os valores deste trabalho foram superiores ao encontrado por Fuchs et al. (2005), que encontraram $77,85 \%$ ao estudar "Iogurte" de soja suplementado com oligofrutose e inulina.

Quanto ao teor de cinzas, não houve diferença significativa entre as formulações, pois mesmo com o incremento dos prebióticos, eles não apresentam um conteúdo mineral suficiente para causar mudança no percentual deste parâmetro. Mesquita et al. (2012), ao estudar iogurte com adição do tamarindo "doce" (Tamarindus indica L.), encontraram um valor superior de cinzas ao estudado nesse trabalho, sendo ele de $0,73 \%$.

A porcentagem de lipídeos encontrada nas três formulações não apresentou diferença significativa entre as amostras, eambas encontram-se de acordo com o conteúdo de matéria gorda estabelecido pela legislação para iogurtes integrais, que varia de 3,0 a $5,9 \mathrm{~g} / 100 \mathrm{~g}$ (BRASIL, 2007). Com isso, observa-se que não houve interferência significativa dos prebióticos sobre o conteúdo lipídico das formulações, permanecendo os mesmos na faixa de 3,0 a $3,1 \%$. Os resultados obtidos estão em concordância os encontrados por Capitani et al. (2014) e Cunha et al. (2008), que obtiveram teor lipídico de 3,0\% ao caracterizarem iogurtes com fibra solúvel e probióticos, respectivamente.

\section{Análise sensorial}

As médias das notas de aceitabilidade dos atributos analisados nos iogurtes, constantes na ficha de avaliação sensorial, estão apresentadas na Tabela 3.

Quanto ao sabor, pôde-se perceber que não houve diferença estatística entre as formulações, uma vez os prebióticos são fisicamente desprovidos de sabor e aroma. Embora, em muitos casos, consigam contribuir para uma maior percepção dos sabores das frutas utilizadas nas formulações de produtos (PIMENTEL et al., 2012).

No que diz respeito a cor, sendo ela um dos primeiros atributos avaliados pelo consumidor e que influencia diretamente na aceitação do produto e na intenção de compra (BEZERRA, 2010), também não foi notada diferença estatística. As médias obtidas (Tabela 3) ficaram entre 7,20 e 7,32, que corresponde a "gostei moderadamente" na escala hedônica.

Com relação ao aroma, cabe considerá-lo como sendo outro importante atributo em produtos, principalmente à base de frutas, já que o consumidor associa o produto intrinsicamente à fruta utilizada. Neste aspecto, percebe-se que não ocorreu diferença estatística entre as amostras, sendo que as três formulações apresentaram nota na

Tabela 3 - Médias dos parâmetros sensoriais aplicados para as formulações de iogurtes

\begin{tabular}{lccc}
\hline \multirow{2}{*}{\multicolumn{1}{c}{ Atributos }} & \multicolumn{3}{c}{ Formulações } \\
\cline { 2 - 4 } & A & B & C \\
\hline Sabor & $6,90^{\mathrm{a}} \pm 1,80$ & $7,32^{\mathrm{a}} \pm 1,25$ & $7,28^{\mathrm{a}} \pm 1,51$ \\
Cor & $7,20^{\mathrm{a}} \pm 1,32$ & $7,32^{\mathrm{a}} \pm 1,11$ & $7,28^{\mathrm{a}} \pm 1,14$ \\
Aroma & $7,20^{\mathrm{a}} \pm 1,33$ & $7,18^{\mathrm{a}} \pm 1,35$ & $7,02^{\mathrm{a}} \pm 1,50$ \\
Consistência & $7,55^{\mathrm{a}} \pm 1,41$ & $7,72^{\mathrm{a}} \pm 1,09$ & $7,77^{\mathrm{a}} \pm 1,15$ \\
Impressão Global & $7,10^{\mathrm{a}} \pm 1,45$ & $7,27^{\mathrm{a}} \pm 1,41$ & $7,03^{\mathrm{a}} \pm 1,54$ \\
\hline
\end{tabular}

*Formulação A (controle) - sem adição de prebiótico; Formulação B (3\% de inulina) e Formulação C (3\% de FOS). Valores expressos como média \pm desvio padrão. Letras iguais em uma mesma linha indicam 
escala hedônica equivalente a "gostei moderadamente".

Embora os prebióticos apresentem grupos $\mathrm{OH}^{-}$disponíveis em sua composição, os quais ligam-se facilmente com a água promovendo uma maior viscosidade (KUNTZ et al., 2013), não foi possível notar diferença estatística na consistência dos produtos elaborados. As médias obtidas ficaram entre 7,52 e 7,77 (Tabela 3), enquadrando-se entre "gostei moderadamente" e "gostei muito" na escala hedônica.

Assim como todos os parâmetros anteriores, a impressão global estudada, referente à avaliação geral do produto, não apresentou diferença estatística entre as formulações, sendo elas A $(7,10)$, B $(7,27)$ e C
$(7,03)$. Ou seja, a adição dos prebióticos não causou efeitos negativos na avaliação geral do iogurte. Dessa forma, verificou-se que essa adição foi viável, em especial na formulação B, sendo possível observar uma diferenciação ao produto pelo alto valor nutritivo e aceita- ção igual ao produto padrão.

$\mathrm{O}$ índice de aceitabilidade dos produtos elaborados está apresentado na Tabela 4.

De acordo com Dutcosky (2007), produtos que obtém notas $\geq 70 \%$ no Índice de Aceitabilidade (IA), são considerados produtos aceitos pelos consumidores. Na Tabela 4 é possível observar que todas as formulações foram consideradas aceitas pelos provadores, com IA variando de $77,7 \%$ a $85,5 \%$. Além disso, as amostras com adição de pre-

Tabela 4 - Índice de aceitabilidade dos iogurtes elaborados

\begin{tabular}{lccc}
\hline \multirow{2}{*}{ Atributos } & \multicolumn{3}{c}{ Formulações } \\
\cline { 2 - 4 } & $\mathrm{A}$ & $\mathrm{B}$ & $\mathrm{C}$ \\
\hline Impressão Global (\%) & 78,8 & 80,0 & 77,7 \\
Sabor (\%) & 76,6 & 82,2 & 80,0 \\
Cor (\%) & 80,0 & 81,1 & 81,1 \\
Aroma (\%) & 80,0 & 78,8 & 77,7 \\
Consistência (\%) & 83,3 & 85,5 & 85,5 \\
\hline
\end{tabular}

*Formulação A (controle) - sem adição de prebiótico; Formulação B (3\% de inulina) e Formulação C (3\% de FOS).

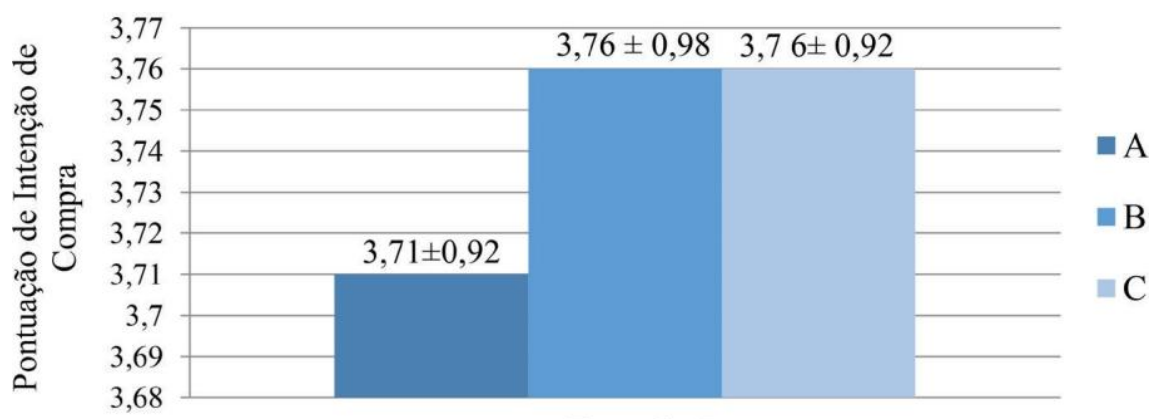

Formulações

Figura 2 - Intenção de compra dos iogurtes 
bióticos se sobressaíram à formulação controle, sendo possível notar a viabilidade de se incrementar compostos prebióticos em produtos lácteos, sem interferência negativa em seus atributos sensoriais.

Para finalizar a avaliação sensorial dos iogurtes formulados, estudou-se também a intenção de compra do produto, que permitiu verificar valores médios atribuídos em torno de 3,7, localizando-se entre os pontos 3 e 4 da escala de intenção de compra, sendo eles: "talvez comprasse/talvez não comprasse o produto" e "possivelmente compraria o produto", respectivamente (Figura 2). Lucia (2008) relata que a descrição sobre a adição de ingredientes funcionais é vista positivamente pelo consumidor e potencializa a sua comercialização, viabilizando, dessa forma, a adição de inulina e FOS para agregação de valores funcionais nos alimentos.

\section{CONCLUSÕES}

O estudo desenvolvido permitiu comprovar a viabilidade da adição de inulina e fruto-oligossacarídeos como importantes ingredientes com propriedades funcionais, sem alterar a maioria dos parâmetros físicoquímicos dos iogurtes produzidos.

Do ponto de vista sensorial, comprovou-se que o produto foi bem aceito pelos provadores e que, estatisticamente, a adição dos prebióticos não interferiu nas características sensoriais estudadas, ficando as formulações B e C com aceitação semelhante a controle, sendo todas viáveis para comercialização.

\section{REFERÊNCIAS}

ALVES, V. et al. Caracterização Parcial e Produção de Fermentado Alcoólico a Base de Tamarindo. In: SLACA - Simpósio Latino Americano de Ciência de Alimentos, 10., Campinas, 2013.
BEZERRA, M. F. Caracterização físicoquímica, reológica e sensorial de iogurte obtido pela mistura dos leites bubalino e caprino. 2010. 116f. Dissertação (Mestrado em Engenharia Química) - Universidade Federal do Rio Grande do Norte, Natal. 2010.

BRAGA, A. C. C.; A. NETO, E. F.; VILHENA, M. J. V. Elaboração e caracterização de iogurtes adicionados de polpa e de xarope de Mangostão (Garcinia mangostana L.). Revista Brasileira de Produtos Agroindustriais, Campina Grande, v. 14, n. 1, p.77-84, 2012. Disponível em: <http://www.deag.ufcg.edu. br/rbpa/rev141/Art1418.pdf >. Acesso em: 30 Jun. 2015.

BRASIL. Ministério da Agricultura, Pecuária e Abastecimento (MAPA). Portaria $n^{\circ} 46$, de 23 de novembro de 2007. Aprova o Regulamento Técnico de Identidade e Qualidade de Leites Fermentados. Diário oficial da República Federativa do Brasil. Brasília, 24 de outubro de 2007, Seção 1, 2007.

CANUTO, G. A. B. et al. Caracterização físico-química de polpas de frutos da Amazô- nia e sua correlação com a atividade anti-ra- dical livre. Revista Brasileira de Fruticul- tura, Jaboticabal, v. 32, n. 4, p. 1196-1205, dez. 2010.

CAPITANI, C. et al. Avaliação físico-química, microbiológica e reológica de bebida láctea e leite fermentado adicionados de probióticos. Revista Brasileira de Tecnologia Agroindustrial, v. 8, n. 2, p. 1285-1300, 2014.

CARVALHO, I; SOUZA, M; PORCU, O.M. Avaliação sensorial de iogurte de uva adicionado de cálcio e zinco. Revista Brasileira de Pesquisa em Alimentos, v. 1, p. 125$128,2010$. 
CECCHI, H. M. Fundamentos teóricos e práticos em análises de alimentos. $2^{\mathrm{a}} \mathrm{ed}$. Ed. Unicamp, São Paulo, 2003. 107 p.

COSTA, M. P. et al. Leite fermentado: potencial alimento funcional. Revista Enciclopédia Biosfera, v. 9, n. 16, p. 1387-1408, jul. 2013.

CUNHA, T. M. et al. Avaliação físico-química, microbiológica e reológica de bebida láctea e leite fermentado adicionados de probióticos. Revista Ciências Agrárias, v. 29, n. 1, p. 103-116, 2008.

DUTCOSKY, S. D. Análise sensorial de alimentos. $2^{\mathrm{a}}$ ed. Curitiba: Editora Champagnat, 2007, $239 \mathrm{p}$

ESTEFE, C. A; ALVES, M. A. R; RIBEIRO, R. L. Próbioticos, prebióticos e simbióticos - artigo de revisão. Saúde e Ambiente em Revista, v. 3, n. 1, p. 16-33, jan./jun. 2008.

FOLCH, J.; LESS, M.; STANLEY, S. A simple method for the isolation and purification of total lipids from animal tissues. Journal Biological Chemistry, v. 226, n. 1, p. 497-509, 1957.

FONTES, C. P. L. M. Produção de oligossacarídeos prébióticos em sucos de frutas. 119 f. 2013. Tese (Doutorado em Biotecnologia industrial) - Universidade Federal do Ceará, Fortaleza. 2013.

FUCHS, R. H. B. et al. Iogurte de soja suplementado com inulina e oligofrutose. Revista Ciência e Tecnologia de Alimentos, Campinas, v. 25, n. 1, p. 10-21, 2005

GARCIA-MARTÍNEZ, M. et al. Valoración nutricional de la composición mineral de yogurtes enteros aromatizados. Alimentaria, v. 35, n. 297, p. 73-76, 1998.
INSTITUTO ADOLF LUTZ. Normas analíticas, métodos químicos e físicos para análises de alimentos. $4^{\mathrm{a}}$ ed., São Paulo, 2008. 1020p.

KARAGUL-YUCEER, Y. et al. Carbonated yogurt - sensory properties and consumer acceptance. Journal of Dairy Science, v. 82, p. 1394-1398, 1999.

KUNTZ, M. G. F.; FIATES, G. M. R.; TEIXEIRA, E. Characteristics of prebiotic food products containing inulin. British Food Journal, v. 115, n. 2, p. 235-251, 2013.

LAGUNA, L. E.; EGITO, A. S. Iogurte batido de leite de cabra adicionado de polpa de frutas tropicais. Circular Técnica, v. 1, n. 32, p. 1-5, dez. 2006.

LUCIA, S. M. D. Métodos estatísticos para avaliação da influência de características não sensoriais na aceitação, intenção de compra e escolha do consumidor. 135f. 2008. Dissertação (Mestrado em Ciência e Tecnologia de Alimentos) - Universidade Federal de Viçosa, Viçosa. 2008.

MARTINEZ, I. et al. Content and in vitro availability of $\mathrm{Fe}, \mathrm{Zn}, \mathrm{Mg}, \mathrm{Ca}$ and $\mathrm{P}$ in homogenized fish-based weaning foods after bone addition. Food Chemistry, v. 63, n. 3, p. 299-305, 1998.

MATSUURA, F. C. A. U.; ROLIM, R. B. Avaliação da adição de suco de acerola em suco de abacaxi visando à produção de um "blend" com alto teor de vitamina C. Revista Brasileira de Fruticultura, v. 24, n. 1, p. 138-141, 2002.

MESQUITA, R. V. S. C. et al. Elaboração, análise físico-química e aceitação do iogurte com adição do tamarindo "doce" (Tamarindus indica L.). Revista Brasileira de Produtos 
Agroindustriais, v. 14, n. 4, p. 381-387, 2012.

OLIVEIRA, M. N. et al. Aspectos tecnológicos de alimentos funcionais contendo probióticos. Revista Brasileira de Ciências Farmacêuticas, v. 38, n. 1, p. 1-21, mar. 2002.

PIMENTEL, T. C; GARCIA, S; PRUDENCIO, S. H. Aspectos funcionais, de saúde e tecnológicos de frutanos tipo inulina. Revista Boletim CEPPA, v. 30, n. 1, p. 103-118, jan. 2012.

QUEIROZ, M. B. Elaboração e caracterização físico-química e sensorial de iogurte prebiótico de acerola. 42 f. 2014. TCC (Técnico em Alimentos). Instituto Federal de Educação, Ciência e Tecnologia do Rio Grande do Norte, Campus Pau dos Ferros, Pau dos Ferros. 2014.

ROJAS, R. M. et al. Contenido mineral del yogurt natural. Alimentaria, v. 30, n. 239, p. 81-84, 1993.
SAAD, S. M. I. Probióticos e prebióticos: o estado da arte. Revista Brasileira de Ciências Farmacêuticas, v. 42, n. 1, p. 1-16, 2006.

SANTOS, K. A. et al. Avaliação das características sensoriais e físico-químicas de iogurte adicionado de inulina. Revista Uniabeu, v. 7, n. 15, p. 50-65, 2014.

SILVA, C. E. V. Produção enzimática de fruto-oligossacarídeos (FOS) por leveduras a partir do melaço-de-cana. 53f. 2008. Dissertação - (Mestrado em Ciência e Tecnologia de Alimentos) - Escola Superior de Agricultura "Luiz de Queiroz", Universidade de São Paulo, Piracicaba. 2008.

SLAVIN, J. Fiber and prebiotics: mechanisms and health benefits. Nutrients Reviews, v. 5, n. 3, p. 1417-1435, 2013.

TACO. Tabela Brasileira de Composição de Alimentos. Versão 2. $2^{\mathrm{a}}$ ed. Núcleo de Estudos e Pesquisas em Alimentação - NEPA. Universidade Estadual de Campinas

- UNICAMP MDS/MS. 2006. 